\title{
IL-12 immunotherapy of minimal residual disease in murine models of HPV16-associated tumours: Induction of immune responses, cytokine production and kinetics of immune cell subsets
}

\author{
MARIE INDROVÁ, JANA BIEBLOVÁ, JAN BUBENÍK and MILAN REINIS \\ Institute of Molecular Genetics, v.v.i., Academy of Sciences of the Czech Republic, Prague 4, Czech Republic
}

Received September 7, 2007; Accepted November 12, 2007

\begin{abstract}
We have established animal models of HPV16associated tumours with distinct levels of MHC class I expression. This model was used for examination of immune responses, production of cytokines and kinetics of immune cell subsets after IL-12 therapy of minimal residual tumour disease induced by CBA-4A (cyclophosphamide derivative) treatment. Upregulation of cytokine production was detected, compared to control animals without tumours. No differences in Th1/Th2 polarization of the immune responses after immunotherapy in animals bearing tumours with different surface expression of MHC class I molecules were observed. In the spleens of TC-1 (MHC class $\mathrm{I}^{+}$) but not of TC-1/A9 (MHC class $\mathrm{I}^{-}$) treated tumour-bearing animals, the cytotoxic $\mathrm{CD} 8{ }^{+}$cells detectable in ${ }^{51} \mathrm{Cr}$ microcytotoxicity assay, were found. In the spleens of TC-1/A9 but not of TC-1 tumourtreated animals, the NK activity measured as the lysis of NK-sensitive YAC-1 targets was detected. Down-regulation of the $\mathrm{CD}^{+}$and $\mathrm{CD}^{+}$subpopulations in spleens of tumourbearing animals were not restored after therapy. The percentage of $\mathrm{CD}^{2} 5^{+/ C D} 4^{+} \mathrm{T}$ regulatory $\left(\mathrm{T}_{\text {reg }}\right)$ cells in lymph nodes remained unchanged. The cytoreductive chemotherapy led
\end{abstract}

Correspondence to: Dr Marie Indrová, Institute of Molecular Genetics, v.v.i., Academy of Sciences of the Czech Republic, Vídenská 1083, 14220 Prague 4, Czech Republic

E-mail: indrova@img.cas.cz

Abbreviations: HPV, human papilloma virus; MHC, major histocompatibility complex; B6, C57BL/6; mAb, monoclonal antibody; IL-12, interleukin 12; FACS, fluorescence-activated cell sorter; CMRTD, minimal residual tumour disease after cytoreductive chemotherapy; NK, natural killers; $\mathrm{T}_{\text {reg }}$, $\mathrm{T}$ regulatory cells; IMC, immature myeloid $\mathrm{Gr}-1^{+} / \mathrm{CD} 11 \mathrm{~b}^{+}$cells

Key words: HPV16, MHC class I-positive and -deficient tumours, minimal residual tumour disease, vaccines, CTLs, NK cells, CD8 ${ }^{+}$ and $\mathrm{CD} 4{ }^{+}$cells, Th1/Th2 polarzation, immature myeloid cells to strong upregulation and accumulation of immunosuppressive immature myeloid $\mathrm{Gr}-1^{+} / \mathrm{CD} 11 \mathrm{~b}^{+}$cells (IMC) in the spleens of treated animals. The accumulation of $\mathrm{Gr}-1^{+} / \mathrm{CD} 11 \mathrm{~b}^{+}$cells was significantly decreased after subsequent IL-12 immunotherapy. These data suggest that elimination of IMC after IL-12 immunotherapy may be responsible for the improvement of antitumour responses after adjuvant IL-12 vaccination for the treatment of CMRTD.

\section{Introduction}

Interleukin 12 (IL-12) has been found in experimental animal models to be one of the most effective cytokines in cancer therapy (1). The broad antitumour activity of IL-12 is likely related to its ability to target multiple cell populations including antigen-specific T cells, NK and NKT cells and antigenpresenting cells (2-4). The mechanisms of IL-12 antitumour effects involve the development of Th1 cells. Interleukin 12 plays also a role in the activation of IFN $\gamma$ production by NK and $\mathrm{T}$ cells and in T cell development (5).

The efficacy of the treatment with recombinant IL-12 or cellular vaccines engineered to produce IL-12 have been shown in the treatment of minimal residual tumour disease after surgery or chemotherapy $(6,7)$. Depending upon the tumour system, differential effectors are stimulated and may be involved in the antitumour response generated either by IL-12 alone (8) or after chemotherapy (9-12).

Cyclophosphamide is a DNA-alkylating chemotherapeutic agent with striking immunomodulatory properties that are widely used in cancer immunotherapy (13). Early results suggested that cyclophosphamide is an inhibitor of suppressor $\mathrm{T}$ cells induced in tumour bearers (14). Further studies have showed that cyclophosphamide induces development of spleen early myeloid cells (15). Recently (16), it has been demonstrated that these myeloid suppressor $\mathrm{Gr} 1^{+} / \mathrm{CD} 11 \mathrm{~b}^{+}$ cells accumulate in the spleens of tumour-bearing animals and contribute to immunosupression in tumour bearers. Therefore, elimination of these cells may improve the antitumour response in cyclophosphamide-treated individuals.

As we have shown previously (17), local immunotherapy with genetically modified tumour cell vaccines, expressing HPV16 E6 and E7 oncogenes and engineered to produce IL-12, can inhibit the growth of early tumour transplants of 
HPV16-associated tumours, as well as the recurrences after cytoreductive chemotherapy.

In this study, using a model of minimal residual tumour disease after cytoreductive chemotherapy (CMRTD) with the cyclophosphamide derivative CBM-4A and subsequent immunotherapy with IL-12-produced tumour vaccines, we analyzed the changes in the immunological characteristics of treated animals, important for successful therapy. Specially we examined changes in Th1/Th2 polarization, the presence of $\mathrm{CD} 25^{+} / \mathrm{CD} 4^{+} \mathrm{T}_{\text {reg }}$ and immature myeloid $\mathrm{Gr}-1^{+} / \mathrm{CD} 11 \mathrm{~b}^{+}$ cells. Additionally, the cytotoxic activity of distinct effector cell populations during tumour growth and therapy was investigated. For these purposes, the murine experimental tumours (TC-1, TC-1/P3C10, TC-1/A9 and MK16/1/III/ABC) expressing HPV16 E6 and E7 oncoproteins with distinct expression of MHC class I molecules, established and transplanted in syngeneic C57/BL6 (B6) mice and mimicking human HPV16-associated neoplasms were utilized. The results show that spleen cells from mice subjected to this cytoreductive chemotherapy and subsequent adjuvant immunotherapy exhibited the cytotoxic effect measured in vitro, and substantial upregulation of Th1/Th2 cytokines. The adjuvant IL-12 immunotherapy accelerated down-regulation of immature myeloid $\mathrm{Gr}-1^{+} / \mathrm{CD} 11 \mathrm{~b}^{+}$suppressor cells, which were upregulated by chemotherapy. The treatment had no effect on down-regulated $\mathrm{CD} 4^{+} / \mathrm{CD}^{+}$lymphocytes in the spleens of the tumour-bearing animals.

\section{Materials and methods}

Mice. C57BL/6 (B6) male mice, 8-10-weeks old, were obtained from AnLab Co., Prague, Czech Republic.

Cell lines. HPV16-associated, non-metastasizing, MHC class I positive cell line TC-1, immunogenic in syngeneic B6 mice (17) and two sublines of TC-1, including TC-1/P3C10 displaying a marked down-regulation of MHC class I molecules, kindly provided from the laboratory of Dr T.C. Wu (Dr ChienFu Hong), Johns Hopkins University, Baltimore, MD, and TC-1/A9 tumour cell line, deficient in MHC class I molecules were used $(18,19)$. As a second model, spontaneously metastasizing, HPV16-associated MK16/1/IIIABC (MK16) tumour cell line, also MHC class I deficient, was also utilized $(19,20)$. The selected cloned sublines, IL-12-gene modified cells MK16-IL-12 (241/clone 33) and TC-1-IL-12 (231/clone 15) cells were used for vaccination (in vitro production: $40 \mathrm{ng}$ IL-12/1×10 cells/ml medium/48 h (7; Vonka and Sobotková, unpublished data). The cell lines were maintained in RPMI1640 medium supplemented with $10 \%$ fetal calf serum, $2 \mathrm{mM}$ L-glutamine and antibiotics (complete medium) and were cultured at $37^{\circ} \mathrm{C}$ in a humified atmosphere with $5 \% \mathrm{CO}_{2}$. For the transduced cell lines, HAT selection medium was used. TC-1/A9 cells were maintained in d-MEM medium, also supplemented with $10 \%$ fetal calf serum, $2 \mathrm{mM}$ L-glutamine and antibiotics.

Therapeutic protocol. For induction of CMRTD, B6 mice were inoculated s.c. with $1 \times 10^{5}$ tumour cells. After $\sim 15$ days, when the tumours reached a size of $2-3 \mathrm{~mm}$ in diameter, the mice were randomly divided into groups ( 8 mice per group) and injected i.p. with $150 \mathrm{mg} / \mathrm{kg}$ of bromine-substituted derivative of ifosfamide CBM-4A (racemic chlorobromofosfamide) preparation (7,21-24). A week later, the mice were injected with a single dose of IL-12-producing, irradiated (150 Gy) TC-1 or MK16 cells ( $1.5 \times 10^{7}$ cells per mouse), in the vicinity of the s.c. tumours, or, twice a day, for two five-days cycles, with rIL-12 (R\&D Systems, Minneapolis, MN, daily dose $0.5 \mu \mathrm{g} / \mathrm{mouse})$. As control vaccines, genetically unmodified irradiated TC-1 or MK16 cells were used. The growing tumours were checked twice a week. The control groups, the 'chemotherapy only', 'rIL-12 or IL-12 producing vaccines only' were inoculated along with the experimental groups.

Flow cytometry. The MHC class I molecule expression on the tumour cells was determined by flow cytofluorometry with PE-labelled anti-mouse H-2K $\mathrm{K}^{\mathrm{b}}$ (AF6-88.5), H-2D ${ }^{\mathrm{b}}$ (KH95) $\mathrm{mAb}$. To determine CD4, CD8 and NK1.1 and CD25 positive cells, the FITC anti-mouse CD4 (L3T4) (RM4-4), FITC antimouse CD8a (Ly-2), (clone 53-6.7), PE anti-mouse NK1.1 NKR-P1B and NKR-P1C (PK136) and anti-mouse CD25 (IL2-Receptor-Chain p55) (PC61) were used. To determine GR-1/CD11b positive cells, FITC anti-mouse CD11b (integrin alpha $_{\mathrm{M}}$ chain, Mac-1 alpha chain) (M1/70) and PE anti-mouse Ly-6G (Gr-1) were used. As isotype controls, FITC and PE-labelled antibody of irrelevant specifity were used. All products were purchased from Pharmingen, San Diego, CA. Flow cytometry was performed using LSR II flow cytometer (BD Biosciences, San Jose, CA).

Cytometric bead array (CBA) analysis. Supernatants obtained after 48 -h cultivation of spleen lymphocyes $\left(2 \times 10^{6} / \mathrm{ml}\right.$ erythrocytes were removed with ammonium chloridepotassium lysing buffer) were frozen. The CBA assay kit (BD Biosciences, San Diego, CA) allowing simultaneous detection and quantification $(\mathrm{pg} / \mathrm{ml})$ of soluble murine IL-2, IL-4, IL-5, IFN $\gamma$ and TNF $\alpha$ in a single sample, was used according to the manufacturer's instructions.

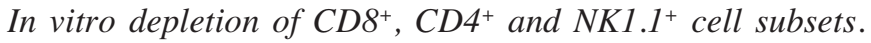
Spleen cells collected from three immunized or naive (control) mice were treated with ammonium chloride-potassium lysing buffer $(1 \mathrm{~min})$ to deplete erythrocytes. The nylon wool-nonadherent (effluent) cells were collected and adjusted to the concentration of $10^{7}$ cells $/ \mathrm{ml}$, and then purified by incubation with monoclonal antibodies against CD8 (2.43), CD4 (GK1.5) and NK1.1 (PK136) specifities to a concentration between $50-500 \mathrm{ng} / \mathrm{ml} / 10^{7}$ cells, together with complement (Baby rabbit complement, Cedarlane, Hornby, Ontario, Canada) for $45 \mathrm{~min}$ at $37^{\circ} \mathrm{C}$.

${ }^{51} \mathrm{Cr}$ microcytotoxicity assay. The cytolytic activity of the spleen effector cells was tested using the ${ }^{51} \mathrm{Cr}$ release assay, as described previously $(19,25-27) .{ }^{51} \mathrm{Cr}$-labelled tumour targets were mixed with the effector cells in various target-toeffector cell ratios in complete RPMI medium supplemented with mercaptoethanol $\left(10^{-5} \mathrm{M}\right)$. The mixtures were incubated in triplicate in 96-well microtiter plates (Nunc, Roskilde, Denmark). Percent of specific ${ }^{51} \mathrm{Cr}$ release was expressed: $[(\mathrm{cpm}$ experimental release - cpm control release) / (cpm 
maximum release - cpm control release)] x 100. As target cells, TC-1 and TC-1/A9- IFN $\gamma$ (MHC I-positive cells, prepared after 72-h cultivation of MHC I-negative TC-1/A9 cells in the medium supplemented with $50 \mathrm{U} / \mathrm{ml}$ IFN $\gamma-\mathrm{RD}$ Systems, Minneapolis, MN) were utilized (19). For in vitro studies of NK activity, YAC-1 cells (28), as a prototype of cells sensitive to natural killers (NK) and C1498 cells, relatively resistant to NK cell-mediated cytolysis (29) were used.

Statistical analyses. For statistical analyses, Student's t-test and the analysis of variance from NCSS (Number Cruncher Statistical System, Kaysville, UT) statistical package were used.

\section{Results}

Therapy of CMRTD with rIL-12 or IL-12-producing vaccines. As shown in Fig. 1, therapy of TC-1, TC-1/P3C10 or TC1/A9 tumours after one injection of IL-12 gene-modified vaccines or with repeated doses of rIL-2 significantly inhibited tumour growth as compared to the untreated controls. No significant difference in the efficacy of recombinant IL-12, TC-1-IL-12, and MK16-IL-12 vaccines was found. The treatment with irradiated, genetically unmodified control vaccines MK16 or TC-1 as well as therapy of the established tumours with rIL-12 alone or with IL-12-producing vaccines was without any significant effect. Similarly, no substantial effect of adjuvant therapy of CMRTD induced on the MK16 tumours was observed.

Changes in the lymphocyte subpopulations during the tumour growth and therapy. During tumour growth, chemotherapy and subsequent adjuvant immunotherapy, the percentages of $\mathrm{CD}^{+}$, and $\mathrm{CD}^{+}$, cells in the spleens of the tumour-bearing animals were significantly decreased. This decrease of $\mathrm{CD}^{+}$and $\mathrm{CD}^{+}$cells was not restored after chemotherapy or subsequent adjuvant immunotherapy (Fig. 2). The amount of $\mathrm{CD} 25^{+} / \mathrm{CD}^{+}{ }^{+} \mathrm{T}$ regulatory (Treg) cells remained unchanged (Fig. 3).

Cytokine production. Chemotherapy and subsequent IL-12 immunotherapy of MHC class I-positive TC- 1 tumours with the TC-1-IL-12 vaccine, led to significant upregulation of Th1 cell-produced cytokines IL- 2 and IFN $\gamma$ by spleen cells. Significant upregulation of IL-5, but not IL-4 (Th2- cytokines) was observed in both MHC class I positive and negative tumour-bearing animals (Table I). The cytokine production was higher in tumour-bearing animals compared to the healthy controls.

Cytolytic activities of lymphocytes. In the spleens of TC-1 (MHC class $\mathrm{I}^{+}$) but not of TC-1/A9 (MHC class I-) tumourbearing animals, specific cytotoxic cells, detectable in ${ }^{51} \mathrm{Cr}$ microcytotoxicity assay were found. To investigate the participation of distinct cell populations, the spleen-derived lymphocytes were treated with monoclonal antibodies against CD4, CD8 and NK 1.1, in the presence of complement. The specific cytotoxic activity was removed after depletion of $\mathrm{CD}^{+}$population and persisted after removing $\mathrm{CD}^{+}$and NK $1.1^{+}$cells (Fig. 4). On the other hand, cytotoxic activity

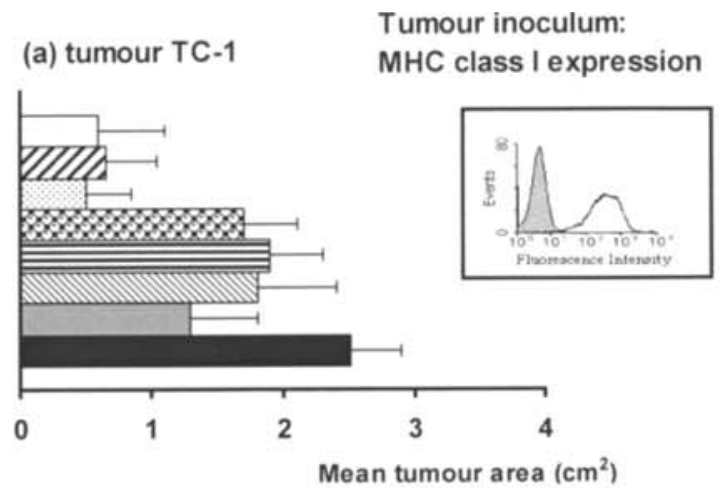

(b) tumour TC-1/P3C10

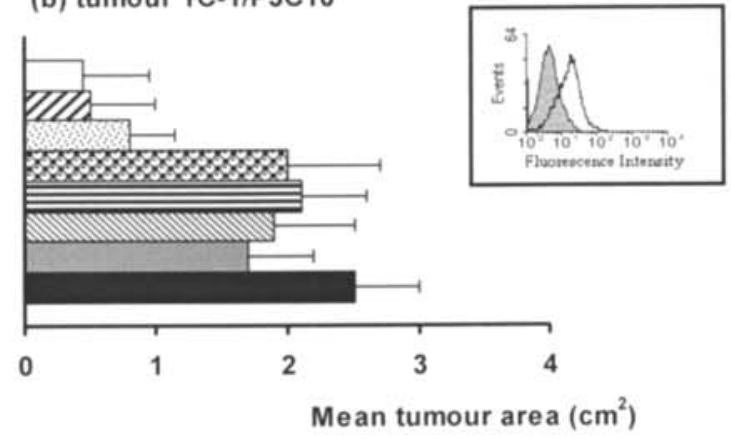

(c) tumour TC-1/A9

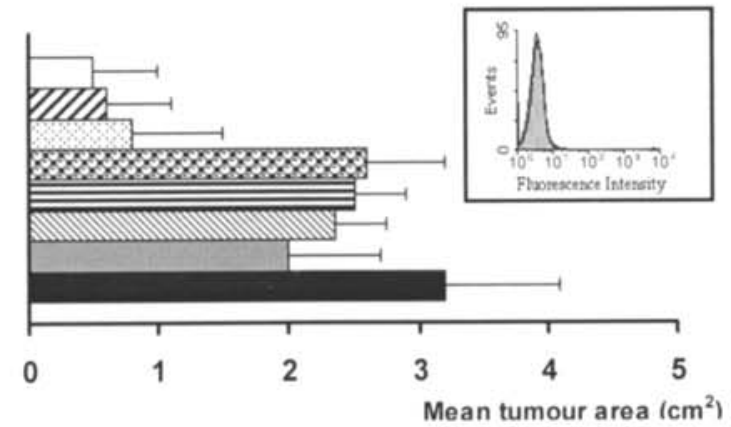

(d) tumour MK16
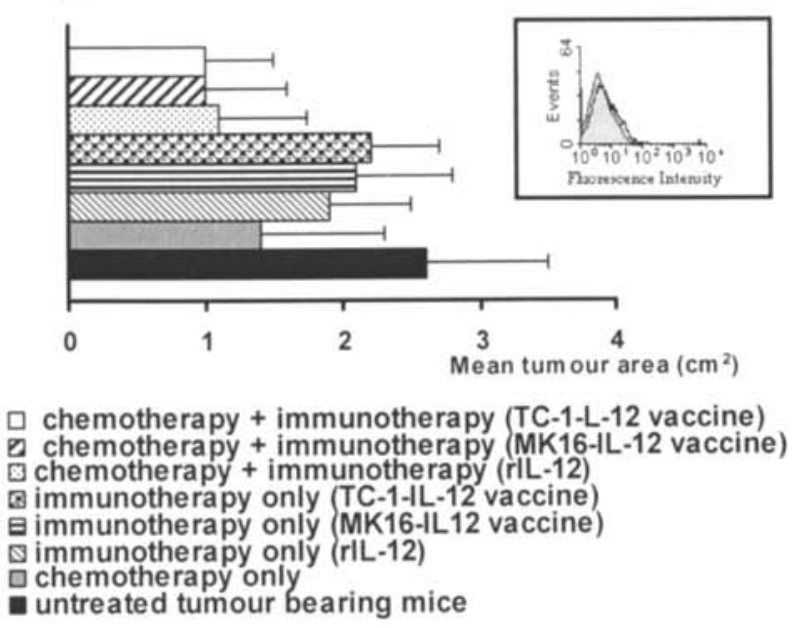

Figure 1. Inhibition of tumour growth after chemotherapy and subsequent immunotherapy with peritumoural administration of rIL-12 or IL-12producing vaccines. Significant inhibition of tumour growth $(\mathrm{p}<0.05)$ was observed in the groups of untreated tumour-bearing mice compared to chemotherapy only groups (a-d); chemotherapy only compared to chemotherapy + subsequent immunotherapy $(\mathrm{a}-\mathrm{c})$; untreated tumour-bearing mice compared to chemotherapy + subsequent immunotherapy (a-d). Genetically unmodified control vaccines MK16 or TC-1 were without any effect (data not shown). MHC class I expression on tumour cells before transplantation determined by FACS analysis are shown in inlets. 
(a) TC-1 tumour
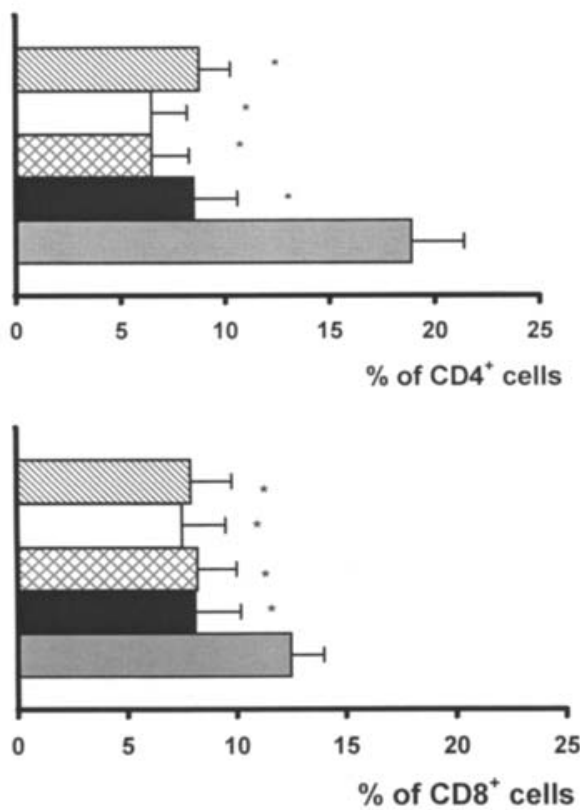

(b) TC-1/A9 tumour
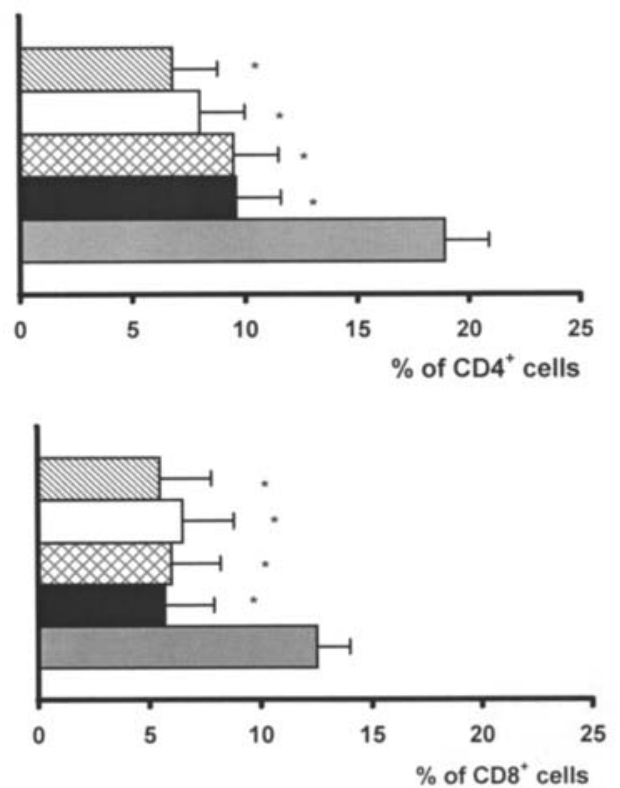

\section{@ chemotherapy + immunotherapy \\ 口immunotherapy only \\ Q chemotherapy only \\ untreated tumor-bearing mice \\ $\square$ healthy controls}

Figure 2. $\mathrm{CD}^{+}$and $\mathrm{CD} 8^{+}$subpopulations decreased in the spleens of TC-1 (MHC class I-positive) and TC-1/A9 (MHC class I-deficient) tumour-bearing mice are not recovered after chemotherapy and subsequent IL-12 therapy with TC-1-IL-12 vaccine. The $\%$ of $\mathrm{CD}^{+}$and $\mathrm{CD} 8^{+}$subpopulations: were decreased $(" \mathrm{p}<0.05)$ in both, treated and untreated animals, compared with the healthy controls. Similar results were obtained after therapy and combined therapy with vaccine MK16-IL-12, as well as with rIL-12, and also after therapy of TC-1/P3C10 and MK16 tumours, respectively (data not shown).

(a) TC-1 tumour

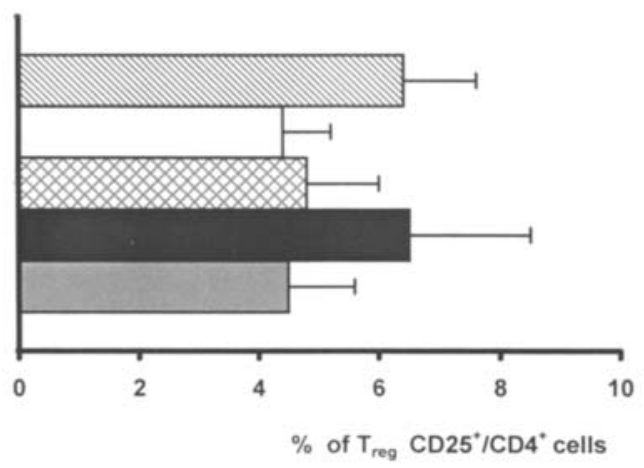

(b) TC-1/A9 tumour

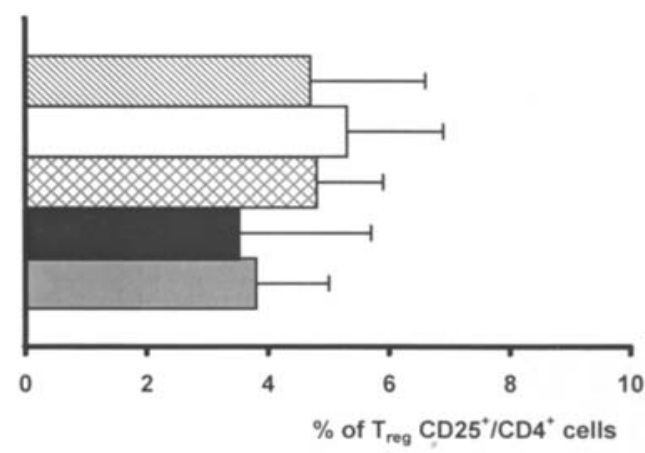

\section{\chemotherapy + immunotherapy \\ $\square$ immunotherapy only \\ $\checkmark$ chemotherapy only \\ untreated tumour-bearing mice \\ 口healthy controls}

Figure 3. The percentage of $\mathrm{T}_{\text {reg }}$ cells was not changed in the regional lymph nodes of tumour-bearing mice of TC-1 (MHC class I-positive) and TC-1/A9 (MHC class I-deficient) during tumour growth, after chemotherapy and subsequent IL-12 therapy with TC-1-IL-12 vaccine. Similar results were obtained after therapy and combined therapy with vaccine MK16-IL-12, as well as with rIL-12, and also after therapy of TC-1/P3C10 and MK16 tumours, respectively (data not shown). 
Table I. Cytokine production by spleen cells from mice after chemotherapy and subsequent IL-12 therapy.

\begin{tabular}{|c|c|c|c|c|}
\hline \multirow[b]{3}{*}{ Spleen cells from ${ }^{\mathrm{a}}$} & \multirow[b]{3}{*}{ Cytokine } & \multicolumn{2}{|c|}{ Cytofluorometric analysis (pg/ml of medium) } & \multirow[b]{3}{*}{ Healthy donors } \\
\hline & & \multicolumn{2}{|c|}{ Tumour-bearing mice } & \\
\hline & & $\begin{array}{c}\mathrm{TC}-1 \\
\left(\mathrm{MHC} \text { class } \mathrm{I}^{+}\right)\end{array}$ & $\begin{array}{c}\text { TC-1/A9 } \\
\left(\mathrm{MHC} \text { class } \mathrm{I}^{-}\right)\end{array}$ & \\
\hline \multirow{5}{*}{$\begin{array}{l}\text { Untreated tumour-bearing mice } \\
\text { bearing mice }\end{array}$} & IL-2 & $36.0 \pm 16.0$ & $45.1 \pm 31.2$ & $11.6 \pm 4.2$ \\
\hline & IL-4 & $5.2 \pm 2.5$ & $6.9 \pm 7.7$ & $1.3 \pm 1.8$ \\
\hline & IL-5 & $1136.0 \pm 64.0$ & $397.0 \pm 252.9$ & $1.9 \pm 5.3$ \\
\hline & $\mathrm{IFN} \gamma$ & $42.0 \pm 27.0$ & $242.2 \pm 163.7$ & $10.3 \pm 8.7$ \\
\hline & $\mathrm{TNF} \alpha$ & $125.0 \pm 152.0$ & $60.7 \pm 54.2$ & $10.1 \pm 11.2$ \\
\hline \multirow[t]{5}{*}{ Chemotherapy only } & IL-2 & $41.0 \pm 4.1$ & $42.2 \pm 21.0$ & $16.8 \pm 7.3$ \\
\hline & IL-4 & $5.4 \pm 1.9$ & $3.6 \pm 1.7$ & $2.9 \pm 2.4$ \\
\hline & IL-5 & $285.0 \pm 6.1^{\mathrm{c}}$ & $189.8 \pm 176.1$ & $17.7 \pm 4.0$ \\
\hline & $\mathrm{IFN} \gamma$ & $57.5 \pm 6.1$ & $145.6 \pm 196.2$ & $94.3 \pm 37.3$ \\
\hline & $\mathrm{TNF} \alpha$ & $20.2 \pm 11.2$ & $87.0 \pm 69.4$ & $30.0 \pm 26.6$ \\
\hline Immunotherapy only (vaccine & IL-2 & $75.5 \pm 13.8$ & $209.2 \pm 60.3$ & $22.3 \pm 3.5$ \\
\hline \multirow[t]{4}{*}{ TC-1-IL-12) } & IL-4 & $13.5 \pm 8.4$ & $19.2 \pm 13.3$ & $1.5 \pm 1.4$ \\
\hline & IL-5 & $1202.2 \pm 195.6^{\mathrm{c}, \mathrm{d}, \mathrm{e}}$ & $1022.3 \pm 415.1^{\mathrm{c}, \mathrm{e}}$ & $17.7 \pm 9.0$ \\
\hline & $\mathrm{IFN} \gamma$ & $942.9 \pm 218.2^{\mathrm{c}, \mathrm{d}, \mathrm{e}}$ & $1080.9 \pm 842.0^{\mathrm{c}, \mathrm{e}}$ & $130.0 \pm 120.0$ \\
\hline & $\mathrm{TNF} \alpha$ & $209.2 \pm 60.3$ & $220.6 \pm 26.3$ & $30.9 \pm 1.8$ \\
\hline \multirow{5}{*}{$\begin{array}{l}\text { Chemotherapy }+ \text { immunotherapy } \\
\left(\text { vaccine TC-1-IL-12) }{ }^{\mathrm{b}}\right.\end{array}$} & IL-2 & $99.9 \pm 63.1^{\mathrm{c}}$ & $248.2 \pm 92.3^{\mathrm{c}}$ & $23.9 \pm 14.5$ \\
\hline & IL-4 & $9.3 \pm 4.8$ & $51.2 \pm 58.6$ & $2.0 \pm 2.0$ \\
\hline & IL-5 & $641.7 \pm 250.9^{\mathrm{c}, \mathrm{d}}$ & $1473.0 \pm 457.6^{\mathrm{c}}$ & $11.5 \pm 11.5$ \\
\hline & $\mathrm{IFN} \gamma$ & $740.7 \pm 246.2^{\mathrm{c}, \mathrm{d}, \mathrm{e}}$ & $491.3 \pm 291.0$ & $22.4 \pm 2.4$ \\
\hline & $\mathrm{TNF} \alpha$ & $72.9 \pm 32.9$ & $41.3 \pm 20.4$ & $21.5 \pm 3.8$ \\
\hline
\end{tabular}

aPool of three mice; the experiment was repeated twice with similar results. ${ }^{b}$ Similar results were obtained after treatment with the MK16IL-12 vaccine or with rIL-12, respectively (data not shown). ${ }^{c} \mathrm{p}<0.05$; as compared to healthy donors. ${ }^{\mathrm{d}} \mathrm{p}<0.05$; as compared to untreated tumour-bearing mice. ${ }^{\mathrm{e}} \mathrm{p}<0.05$; as compared to chemotherapy only group.

of NK $1.1^{+}$cells, measured as the percent of specific lysis of YAC-1 targets, was detected in the spleens of TC-1/A9 (MHC class $\mathrm{I}^{-}$) treated tumour-bearers (Fig. 5). The cytotoxic activity of NK1.1+ cells was not observed in TC-1 (MHC class $\mathrm{I}^{+}$) tumour-treated animals.

Effects on immature myeloid $\mathrm{Gr}-\mathrm{I}^{+} / \mathrm{CD} 11 \mathrm{~b}^{+}$cells. The cytoreductive chemotherapy alone (ifosfamide derivative CBM-4A) led to the upregulation and accumulation of immature myeloid Gr- $1^{+} / \mathrm{CD} 11 b^{+}$cells (IMC) in the spleens of treated animals, which was significantly decreased after subsequent IL-12 immunotherapy (Fig. 6). These results suggest that IL-12 treatment could contribute to made rapid elimination of IMC.

\section{Discussion}

Immunotherapy with cellular vaccines engineered to produce IL-12 has been shown to be effective in the treatment of minimal residual tumour disease after chemotherapy. Importantly, the therapeutic effects have been observed on both MHC class I-positive and -deficient experimental tumours (7). In this study, we have focused on the detailed analyses of the mechanisms underlying the immunotherapeutic effects of IL-12 used for the treatment of minimal residual tumour disease after chemotherapy. We paid special attention to the differences in immune responses between MHC class I-positive and -deficient tumours. Since it is known that cyclophosphamide and its derivatives play an active role in modulation of immune responses, we raised the question of how CBM-4A treatment can influence the activation of the immune system with IL-12, either in tumour-free or in tumour-bearing animals.

First, we have documented, using four E6/E7 expressing tumour cell lines, that the treatment with IL-12-producing tumour cell lines was effective against both MHC class $\mathrm{I}^{-}$ positive and -deficient experimental tumours. As shown previously (7), this therapy was successful only on TC-1 and 


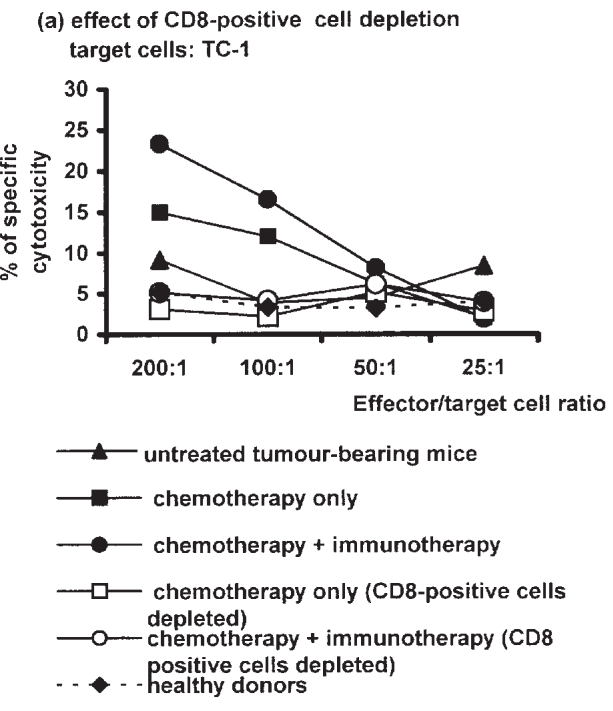

(c) effect of CD8 and CD4-positive cell depletion target cells: YAC-1

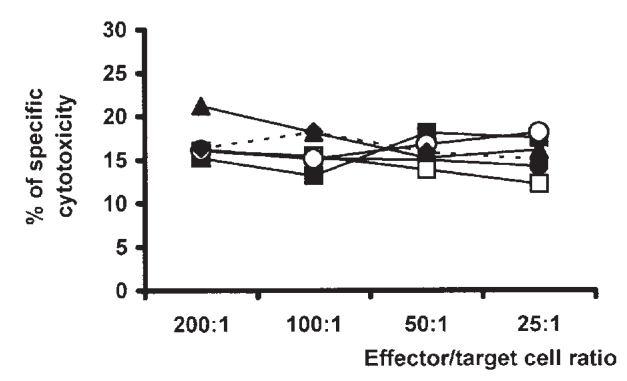

(b) effect of CD4 and NK1.1-positive cell depletion target cells: TC-1
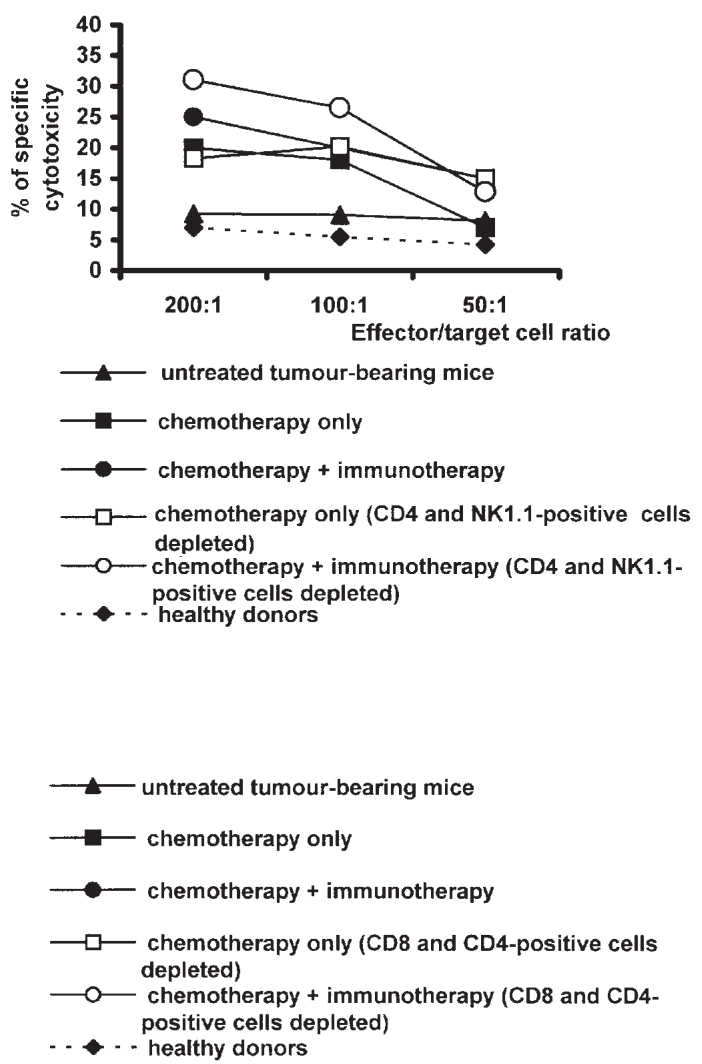

Figure 4. Chemotherapy and subsequent immunotherapy with TC-1-IL-12 vaccine of TC-1 (MHC class I-positive) tumours activate generation of the CD8+ cytotoxic lymphocytes in vitro. Cytotoxic effect $(\mathrm{p}<0.05)$ in the spleens of chemotherapy only and chemotherapy and subsequent immunotherapy treated mice compared to the effect in treated tumour-bearing or on the healthy donors was observed (a and $b)$. This cytotoxic effect was abrogated after depletion of CD ${ }^{+}$ cells (a). The $\mathrm{CD}^{+}$and NK1.1+-depleted cells were ineffective (b), as well as $\mathrm{CD}^{+}+{ }^{+} \mathrm{CD} 8^{+}(\mathrm{c})$. The cytotoxic effect was determined by ${ }^{51} \mathrm{Cr}$ microcytotoxic assay; target cells: TC-1, YAC-1.

TC-1-derived tumours and similar results were also obtained after surgical therapy of these tumours (30). However, the treatment of established tumours unlike the therapy of early transplants (7) with rIL-12 or with IL-12- producing vaccines was without any significant effect. On the other hand, adjuvant immunotherapy had no significant effects on another MHC class I-deficient line MK16. These data suggest that the difference in sensitivity between MK16 and TC-1 cells could not be explained merely by differences in the MHC class I expression on these tumours. Interestingly, no apparent differences in Th1/Th2 polarization of the immune responses after immunotherapy in animals bearing TC-1 tumour variants with different surface expression of MHC class I molecules were noticed, as determined by the analysis of selected Th1/Th2 expression by the spleen cells. On the contrary, although no differences in Th1/Th2 polarization were noted, we have shown in functional chromium release microcytotoxic tests that IL-12 induced an effective cytotoxic immune reaction, mediated by CTLs, only in animals bearing MHC class I-positive TC-1 tumours. The specific CTL-mediated cytotoxic activity of the spleen cells from animals bearing MHC class I-negative tumours remained under the detection limits of the test. On the other hand, NK activation was observed only in animals with MHC class I-deficient tumours.
Thus, these results indicate that the effects of IL-12 on CTL and NK cells can be modulated by the MHC class I status of the tumours. These results are in agreement with our previous studies in which immunization with irradiated MHC class I-negative but not -positive tumour cells expressing E6/E7 oncoproteins inhibited growth of the MHC class Ideficient tumours expressing the same oncoproteins (31).

Next, we analyzed the influence of the CBM-4A treatments on the capacities of the immune system to respond to IL-12, administered in the form of cytokine-producing tumour vaccines or as recombinant IL-12. Results from our study show that this therapy of tumours can be highly effective. This effectiveness is likely dependent on T cells (MHC class I-positive tumour), although a significant decrease in the number of $\mathrm{CD}^{+}$and $\mathrm{CD}^{+}$cells was observed. Cyclophosphamide and its derivatives are known to modulate cell lineages with immunosuppressive functions, namely $\mathrm{T}_{\text {reg }}$ and IMC $(32,33)$. While the effects on the $\mathrm{T}_{\text {reg }}$ can stimulate the antitumour immunity, accumulation of IMC is known to be an immunosuppressive mechanism (34). Therefore, rapid elimination of the IMC after chemotherapy could contribute to elimination of the recurrent tumours by the immune system.

Taken together, we have documented that effective treatment of the minimal tumour disease after chemotherapy 
(a) effect of CD4 and NK1.1-positive cell depletion target cells: TC-1-A9/IFNgamma

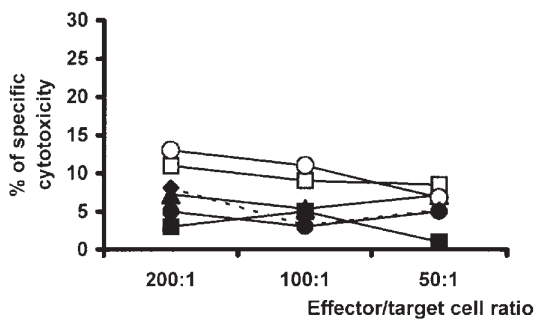

$\longrightarrow$ untreated tumour-bearing mice

$\longrightarrow$ - chemotherapy only

$\longrightarrow$ chemotherapy + immunotherapy

- - chemotherapy only (CD4 and NK1, 1-positive

- cells depleted)

positive cells depleted)

. . healthy donors

(c) effect of CD8 and CD4-positive cell depletion target cells: YAC - 1

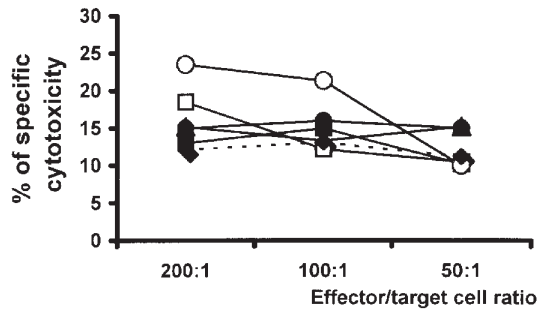

(b) effect of CD8 and CD4-positive cell depletion target cells: TC-1/A9-IFNgamma

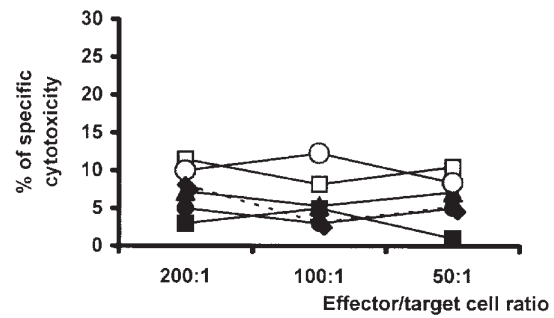

$\longrightarrow$ untreated tumour-bearing mice

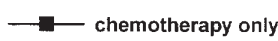

- chemotherapy + immunotherapy

$-\square-$ chemotherapy only (CD8 and CD4-positive cells depleted) chemotherapy + immunotherapy (CD8 and CD4positive cells depleted)

- - - positue cells deplete

Figure 5. Chemotherapy and subsequent immunotherapy with TC-1-IL-12 vaccine of TC-1/A9 (MHC class I deficient) tumours activates NK1.1 cells in vitro. $\mathrm{p}>0.05$ ( $\mathrm{a}$ and $\mathrm{b})$. A cytotoxic effect $(\mathrm{p}<0.05)$ of spleen cells from mice treated with chemotherapy and subsequent immunotherapy, CD4 ${ }^{+}$and $\mathrm{CD} 8^{+}-\mathrm{depleted,}$ against YAC-1 targets was found (c). The cytotoxic effect was determined by ${ }^{51} \mathrm{Cr}$ microcytotoxic assay; target cells: TC-1/A9-IFN $\gamma$, YAC-1. No lysis of C1498 targets was detected (data not shown).

(a) TC-1 tumour

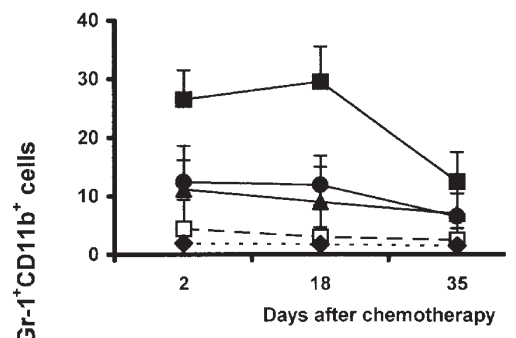

(c) TC-1/A9 tumour

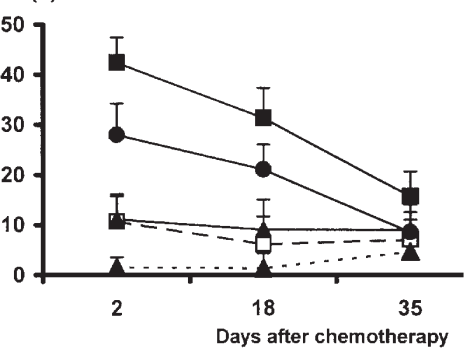

(b) TC-1/P3C10 tumour

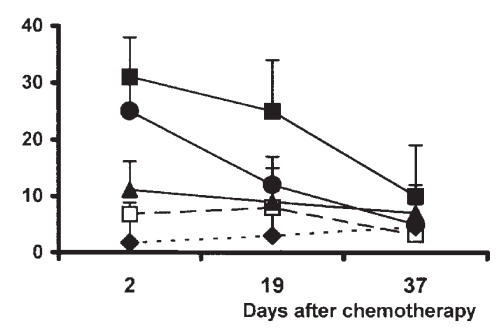

(d) MK16 tumour

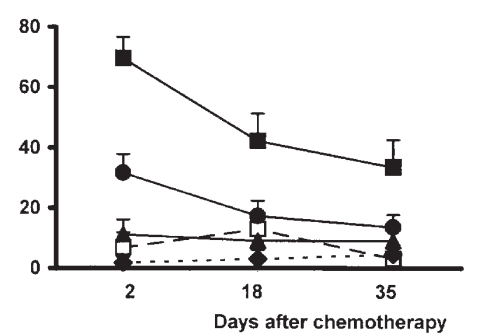

\footnotetext{
- $\square-$ spleen cells from untreated tumour-bearing mice

- spleen cells from chemotherapy only treated mice

splen cells from immunotherapy only treated mice

- spleen cells from chemotherapy + immunotherapy

treated mice
- spleen cells from healthy donors
}

Figure 6. Immature myeloid $\mathrm{Gr}-1^{+} / \mathrm{CD} 11 \mathrm{~b}^{+}$cells: upregulation after the CBM-4A preparation and down-regulation after subsequent IL-12 therapy with TC-1IL-12 vaccine (FACS analysis). $\mathrm{p}<0.05$; chemotherapy only groups compared to the chemotherapy + subsequent immunotherapy (a-d). Similar results were obtained using vaccine MK16-IL-12, as well as with rIL-12 after the same therapy protocol (data not shown). Average accumulation of IMC in the spleens of healthy donors, seven days cells after CBM-4A inoculation, was $30.5 \pm 3.6 \%$. 
with a cyclophosphamide derivative against MHC class Ipositive and -deficient tumours can be mediated by different mechanisms. Moreover, our data suggest that inhibition of the immunosuppression after chemotherapy can be another mechanism underlying the IL-12 effects.

\section{Acknowledgements}

This work was supported by grant no. 301/06/774 from the Grant Agency of the Czech Republic and in part by grant no. AVOZ50520514 awarded by the AS CR, by the grant of the Clinigene project EU-FP6-NOE, no. 018933, by the grant of the Joint Project under the Agreement of Scientific Cooperation between PAN and AS CR (2006-2008). The authors are grateful to Professor Vladimír Vonka for the kind gift of MK16 cells, to Dr Michal Smahel for TC-1/A9, TC-1IL-12 and MK16-IL-12 cells, to Dr Elzbieta Pajtasz-Piasecka for the kind gift of CBM-4A preparation, to Mrs. Renáta Turecková and Marie Malecková for skilful technical assistance, and to Dr Sárka Takácová and Jasper Manning, for editorial help.

\section{References}

1. Tsung K, Dolan JP, Tsung YL and Norton JA: Macrophages as effector cells in interleukin 12-induced T cell-dependent tumor rejection. Cancer Res 62: 5069-5075, 2002.

2. Portielje JE, Gratama JW, van Ojik HH, Stoter G and Kruit WH: IL-12: a promising adjuvant for cancer vaccination (review). Cancer Immunol Immunother 52: 133-144, 2003.

3. Knutson KL and Disis ML: Tumor antigen-specific $\mathrm{T}$ helper cells in cancer immunity and immunotherapy (review). Cancer Immunol Immunother 54: 721-728, 2005.

4. Walzer T, Dalod M, Robbins SH, Zitvogel L and Vivier E: Natural-killer cells and dendritic cells: 'l'union fait la force' (review). Blood 106: 2252-2258, 2005.

5. Tsung K, Meko JB, Tsung YL, Peplinski GR and Norton JA: Immune response against large tumors eradicated by treatment with cyclophosphamide and IL-12. J Immunol 160: 1369-1377, 1998.

6. Mikysková R, Bubeník J, Mendoza L, Vonka V, Smahel M, Símová J and Jandlová T: Local cytokine treatment of HPV16associated tumours results in inhibition of their lung metastases. Clin Exp Metastasis 18: 581-587, 2000.

7. Indrová M, Bieblová J, Jandlová T, Vonka V, Pajtasz-Piasecka E and Reinis M: Chemotherapy, IL-12 gene therapy and combined adjuvant therapy of HPV16-associated MHC class I-proficient and -deficient tumours. Int J Oncol 28: 253-259, 2006.

8. Smyth MJ, Taniguchi M and Street SE: The anti-tumor activity of IL-12: mechanisms of innate immunity that are model and dose-dependent. J Immunol 165: 2665-2670, 2000.

9. Golab J, Zagozdzon R, Kaminski R, Kozar K, Gryska K, Izycki D, Mackiewicz A, Stoklosa T, Giermasz A, Lasek W and Jakobisiak M: Potentiatied antitumor effectiveness of combined chemo-immunotherapy with interleukin-12 and 5-fluorouracil of L1210 leukemia in vivo. Leukemia 15: 613-620, 2001.

10. Le HN, Lee NC, Tsung K and Norton JA: Pre-existing tumorsensitized $\mathrm{T}$ cells are essential for eradication of established tumors by IL-12 and cyclophosphamide plus IL-12. J Immunol 167: 6765-6772, 2001.

11. Segal JG, Lee NC, Tsung YL, Norton JA and Tsung K: The role of IFN-gamma in rejection of established tumors by IL-12: source of production and target. Cancer Res 62: 4696-4703, 2002.

12. Norton JA, Li M, Lee NC and Tsung K: Inhibition of host signal transducer and activator of transcription factor 6 results in cure with cyclophosphamide and interleukin 12 immunotherapy. Ann Surg Oncol 13: 118-124, 2006.

13. Emens LA, Machiels JP, Reilly RT and Jaffee EM: Chemotherapy: friend or foe to cancer vaccines? (review). Curr Opin Mol Ther 3: 77-84, 2001.
14. North RJ: Cyclophosphamide-facilitated adoptive immunotherapy of an established tumor depends on elimination of tumor-induced suppressor T cells. J Exp Med 155: 1063-1074, 1982.

15. Pelaez B, Campillo JA, Lopez-Asenjo JA and Subiza JL: Cyclophosphamide induces the development of early myeloid cells suppressing tumor cell growth by a nitric oxide-dependent mechanism. J Immunol 166: 6608-6615, 2001.

16. Suzuki E, Kapoor V, Jassar AS, Kaiser LR and Albelda SM: Gemcitabine selectively eliminates splenic Gr-1+/CD $11 b^{+}$ myeloid suppressor cells in tumor-bearing animals and enhances antitumor immune activity. Clin Cancer Res 11: 6713-6721, 2005.

17. Lin KY, Guarnieri FG, Staveley-O'Carroll KF, Levitsky HJ, August JT, Pardoll DM and Wu TC: Treatment of established tumors with a novel vaccine that enhances major histocompatibility class II presentation of tumor antigen. Cancer Res 56: 21-26, 1996

18. Smahel M, Sobotková E, Bubeník J, Símová J, Zák R, Ludvíková V, Hájková R, Kovarík J, Jelínek F, Povysil C, Marinov J and Vonka V: Metastatic MHC class I-negative mouse cells derived by transformation with human papillomavirus type 16. Br J Cancer 84: 374-380, 2001.

19. Mikysková R, Bubeník J, Vonka V, Smahel M, Indrová M, Bieblová J, Símová J and Jandlová T: Immune escape phenotype of HPV16-associated tumours: MHC class I expression changes during progression and therapy. Int J Oncol 26: 521-527, 2005.

20. Smahel M, Síma P, Ludvíková V, Marinov I, Pokorná D and Vonka V: Immunisation with modified HPV16 E7 genes against mouse oncogenic TC-1 cell sublines with down-regulated expression of MHC class I molecules. Vaccine 21: 1125-1136, 2003.

21. Glazman-Kusnierczyk H, Matuszyk J and Radzikowski C: Antitumor activity evaluation of bromine-substituted analogues of ifosfamide. I. Stereodifferentiation of biological effects and selection of the most potent compounds. Immunopharmacol Immunotoxicol 14: 883-911, 1992.

22. Indrová M, Bubeník J, Símová J, Bieblová J, Jandlová T, Smahel M, Vonka V, Glazman-Kusnierczyk H, PajtaszPiasecka E, Radzikowski C and Mikysková R: Chemoimmunotherapy of cancer: potentiated effectiveness of granulocytemacrophage colony-stimulating factor and ifosfamide derivative CBM-4A. Oncol Rep 8: 1371-1374, 2001

23. Indrová M, Bubeník J, Mikysková R, Mendoza L, Símová J, Bieblová J, Jandlová T, Jinoch P, Smahel M, Vonka V and Pajtasz-Piasecka E: Chemoimmunotherapy in mice carrying HPV-16 associated, MHC class I and MHC class I tumours: effects of CBM-4A potentiated with IL-2, IL-12, GM-CSF and genetically modified tumour vaccines. Int J Oncol 22: 691-695, 2003.

24. Mikysková R, Indrová M, Símová J, Jandlová T, Bieblová J, Jinoch P, Bubeník J and Vonka V: Treatment of minimal residual disease after surgery or chemotherapy in mice carrying HPV 16-associated tumours: cytokine and gene therapy with IL-2 and GM-CSF. Int J Oncol 24: 161-167, 2004.

25. Bubeník J, Zeuthen J, Indrová M, Bubeníková D and Símová J: Kimetics and function of peritoneal exudate cells during local IL-2 gene therapy of cancer. Int J Oncol 4: 13-16, 1994.

26. Indrová M, Mikysková R, Jandlová T, Vonka V, Bubeník J and Bieblová J: Adjuvant cytokine treatment of minimal residual disease after surgical therapy in mice carrying HPV16-associated tumours: cytolytic activity of spleen cells from tumour regressors. Folia Biol (Praha): 49: 217-222, 2003.

27. Indrová M, Reinis M, Bubeník J, Jandlová T, Bieblová J, Vonka V and Velek J: Immunogenicity of dendritic cell-based HPV16 E6/E7 peptide vaccines: CTL activation and protective effects. Folia Biol (Praha) 50: 184-193, 2004.

28. Wizgel $\mathrm{H}$ and Ramstedt U: Natural killer cells. In: Cellular Immunology. Vol. 2. Weir MM (ed). Blackwell Scientific Publ., Oxford, pp601-609, 1986.

29. Goldie H, Butler CH and Anderson MM: Growth characteristics of free C1498 (granulocytic leukaemia) tumour cells in the peritoneal fluid and the blood of C57 mice. Cancer Res 13: 125-129, 1953.

30. Bubeník J, Mikysková R, Vonka V, Mendoza L, Símová J, Smahel $\mathbf{M}$ and Indrová $\mathrm{M}$ : Interleukin-2 and dendritic cells as adjuvants for surgical therapy of tumours associated with human papillomavirus type 16. Vaccine 21: 891-896, 2003. 
31. Reinis M, Símová J, Indrová M, Bieblová J, Pribylová H, Moravcová S, Jandlová T and Bubeník J: Immunization with MHC class I-negative but not -positive HPV16-associated tumour cells inhibits growth of MHC class I-negative tumours. Int J Oncol 30: 1011-1017, 2007.

32. Salem ML, Kadima AN, El-Naggar SA, Rubinstein MP, Chen Y, Gillanders WE and Cole DJ: Defining the ability of cyclophosphamide preconditioning to enhance theantigen-specific $\mathrm{CD} 8^{+} \mathrm{T}$-cell response to peptide vaccination: creation of a beneficial host microenvironment involving type I IFNs and myeloid cells. J Immunother 30: 40-53, 2007.
33. Angulo I, de las Heras FG, Garcia-Bustos JF, Gargallo D, Munoz-Fernandez MA and Fresno M: Nitric oxide-producing CD11b(+)Ly-6G(Gr-1)(+)CD31(ER-MP12)(+) cells in the spleen of cyclophosphamide-treated mice: implications for T-cell responses in immunosuppressed mice. Blood 95: 212-220, 2000 .

34. Huang B, Pan PY, Li Q, Sato AI, Levy DE, Bromberg J, Divino $\mathrm{CM}$ and Chen SH: $\mathrm{Gr}-1^{+} \mathrm{CD} 115^{+}$immature myeloid suppressor cells mediate the development of tumor-induced $\mathrm{T}$ regulatory cells and T-cell anergy in tumor-bearing host. Cancer Res 66: 1123-1131, 2006. 